\title{
THE IMPACT OF ERP AUDIT ON MEASURING ORGANIZATIONAL PERFORMANCE: THE CASE OF LEBANON
}

\author{
Ali SERHAN \\ Bucharest University of Economic Studies, Romania \\ Serhanali333@gmail.com
}

\begin{abstract}
Fraud scandals have had a negative impact on the public's confidence in financial reporting hence impacting auditing professions. The role of continuous auditing is to ensure auditing credibility and meet Sarbanes-Oxley (SOX) requirements. The research intends to give a literature review on the topic as well as address the models, concepts and implications of continuous auditing. The research aims to study the impact of ERP systems in conducting auditing practices in the organizations. Both primary and secondary data had been implemented to ensure outcomes accuracy. The primary data included a designed questionnaire to collect data and then analyzing them using the SPSS statistical tool. As for the secondary data it is addressed through empirical literature review. The findings proved that there is a positive significant relationship between both ERP and conducting auditing practices in the company, the higher the ERP systems are practiced the higher the auditing practices will be implemented in an efficient and effective way.
\end{abstract}

Keywords: Continuous auditing, business performance, ERP, Internal audit process.

\section{INTRODUCTION}

The role of continuous auditing is to make auditing retable to everyday processes and separate it from the traditional retrospective annual inspection of financial statements (Kanellou \& Spathis, 2011). Continuous auditing and continuous is important for organizations in meeting cooperative objectives and is considered a toll for the augmentation of external audit. They are using them to transform internal audit as well as to create value for their business (Abdolmohammadi \& Boss, 2010). Their implementation is valuable in addressing the evolving and complex risk environments as well as the regulatory and business requirements. The aim of continuous auditing $(C A)$ is to provide transparency as well as timely reporting of concerns. In organizations many departments with the popularity of continuous auditing, are using it as a key element in their audit departments' risk monitoring strategies.

Embedded audit modules (EAM) and Monitoring control layer (MCL) are methodologies for approaching CA in computerized environments. They are software modules that have been built into an information 
system so as to monitor the activities involved. All EPR systems that process business transactions have all been built on a core database management system (DBMS).

\section{Continuous Auditing and Performance}

When it comes to auditing services there has to be consistency of the information that is being examined. Hence, in an auditing process the auditor has the duty of verifying data that is being audited. Auditors need to develop auditing tools to be able to monitor data errors as well as monitor them. The continuous auditing process is very crucial in this regard as it helps modernize and expand finance and report models. Continuous auditing has a number of definitions. (Rezaee et al., 2001) It is defined as, determining how efficient accounting systems are through the process of gathering and evaluating evidence to maintain data integrity, give reliable financial information and to safeguard assets. It also brings together risk and control assessment and other audit technologies and techniques.

In understanding continuous auditing it is important to understand how it relates to traditional auditing. A similarity is that both of them use GAAP (generally accepted accounting principles) as criteria in independent professional attestation services. The auditing methods used by Continuous auditing range from regular control evaluations to control risk assessments that are done on a regular basis.

Continuous auditing has a heavy reliance on information technology as the technology tools that assist in auditing are important. Over the years there has been a lot of technology advancement made on CA including broad bandwidth, web scripting solutions, web application server technology and web service technology. Technology is important for CA as it enables auditors to monitor client systems in the internet using sensors and digital editors. With CA, real-time reporting is required for continuous assurance. A continuous audit is only possible if there is real-time reporting of financial information. Thus organizations have the duty of ensuring that financial figures are made available to the auditors in real-time for it to be effective.

When it comes to implementation and adoption of CA the market, government and organizations are major driving forces. CA implementation is not as fast due to the requirement of financial reports collection in real time. According to a lot of studies done on capital markets, results have shown that markets are moving towards adoption of continuous auditing and reporting. There is a clear relationship that exists between the concepts of $\mathrm{CA}$ and those of $\mathrm{CM}$. For the goals of $\mathrm{CA}$ to be achieved an organization needs to integrate the existing ERP system with an enterprise risk management (ERM).

An ERM program has the function of activity design and control over financial, regulatory fraud and operational risks. When an ERM program is successful there is coordination of internal audit with management hence no duplication of efforts or waste of resources. CA implementation structure has a 
close resemblance to ERP system structure. In the case that an ERP system has multiple loosely coupled applications, a number of CA software's and necessary for targeting each ERP application (Grabski et al., 2011).

ERP data has two types of connections, direct and intermediate. When it comes to direct connection, there is direct access to either application layer or database layer of an ERP system. As much as this is the fastest connection it has the disadvantage of $\mathrm{CA}$ and $\mathrm{CM}$ having to be implemented in the program and programming language. When it comes to intermediate access ERP functions can be triggered from outside the system as well as authenticated services through remote enabled ERP functions.

CA implementation has the capacity of residing on the same platform as an ERP system as well as on different ones. An embedded audit model (EAM) is the implementation that occurs when ERP system hosts CA implementation. If an implementation gets to be hosted in a separate platform it is referred to as Monitoring and Control layer (MCL). Due to this tight relation ERP systems have with EAM model they are prone to manipulation unlike MCLs. When it comes to implementing continuous auditing there are certain demands that are placed on the audit department (Kholeif et al, 2007). They include:

- They are in charge of getting an audit committee and management support.

- Develop technical competences as well as ensure that necessary technology is available.

- Ensure integration and adoption of continuous auditing with risk oriented audit planning.

- Ensure management adopts continuous monitoring and promotes it.

- Drivers for Continuous Auditing implementation

- To run a continuous auditing (CA) system a number of components are necessary.

- Web servers whereby they must be given the permission to communicate.

- The presence of an audit environment.

- A continuous audit agreement must also be there for the involved parties.

- There has to be reliability of the interconnected systems.

- Authorization, confidentiality and authentication of transmitted information.

- $\quad$ Audit reports to show when a user accesses a webpage.

\section{Benefits of Continuous Auditing}

It is a beneficial tool to an organizations reputation as well as governments. This is because the reporting cycle helps to improve an organizations trust as well as the perception of investors.

The users' expectation and perceptions about auditor's abilities and responsibilities to report concerns will increase with continuous reporting in continuous auditing (Searcy et al., 2003)

- It helps reduce the costs involved in assessing internal controls as auditing is made cheaper. 
- There is improvements to the financial operations, reduce financial errors as well as increased profitability of organizations.

- It also helps auditors in detecting fraud.

- It also helps in building the users trust on auditors' abilities and responsibilities.

- There is also increased ability in mitigating business risks.

- It brings transparency for continuous assurance and performance of an organization.

\section{The roles of internal auditing and management}

The role of an internal audit activity is to identify and evaluate how effective risk management system and controls implemented by an organization (Ebaid, 2011). This assessment is usually done in order to assure management on the current state of risk control in the organization. Internal auditing which normally deals with management, collaborates with continuous auditing for overall monitoring of the organization.

\section{ERP and Performance Audit}

When it comes to performance management, it can be best described as the unified working effort between managers and employees to organize, monitor and review employees work objectives and the contribution they make to the organization. Fundamental features of an organization are affected by ERP thus its successful implementation is necessary for performance and survival.

According to Elragal et al. (2011), organizations acquire ERP systems due to their technical gains and improvement of operational performance and efficiency. Its installation and configuration is central to how effectively it performs as effective installation enhances performance and information gathering.

The impact of IT technologies when an organization employs use of information technology produces positive results on productivity (Chen et al., 2012). In order to have significant benefits from an ERP system, it is important to align the business aims with the ERP objectives. Performance management is of major focus due to increasing pressure on organizations to execute better business strategies so as to remain competitive. ERP systems have the goal of supporting business processes in order for them to improve strategic opportunities of organizations.

For this goal to be achieved, constant tracking of goals is crucial as the feedbacks provided are important. Understanding critical areas for success of an organization is a strong starting point for project management. After that, measuring if operations are performing as required is next. When it comes to organizations long-term development, information gathering is needed as it is the basis for planning and decision making. Information gathering has been positively impacted by computerized information systems as more data is now available. There exists dependence with performance measurement and information 
systems. This is because performance measurement is dependent on continuous access to relevant information while information systems act on issues that are based on management challenges. When it comes to performance management and integrated information systems such as ERP systems, advanced planning and decision-making is conducted.

The information needs of management are satisfied through development of information systems (Gosain, S. (2004). ERP systems do not have specific function, type of storage or processing of data. These systems are very important as they are said to also have business perspective as well as termed as comprehensive and complex in nature.

According to Lee and Lee (2000), ERP systems are enterprises wide packages that tightly integrate business functions into a single system that shares database. Despite developments over the years especially on financial measures for performance measurement and ERP systems, traditional measures concerned with financial aspects are still well developed and are large parts of ERP solutions.

ERP systems have differences with traditional systems. First, users may have to make changes to business processes and procedures. Secondly, users may require introduction of customization. Lastly, users may become dependent on ERP vendors for updates and assistance. ERP systems have also grown from human resource management to an efficient tool for IT management. The fact that it entails and performs all the required tasks is an added plus. Unlike ERP systems traditional applications systems perform differently where they generally treat every transaction separately as well as their functions are very specific.

Since the 1990s, ERP has been regarded as an important innovative development in information technology (IT). The fact that most organizations are shifting from the traditional information systems to more process-based IT infrastructure has made ERP systems very wide spread.

Advantages of ERP systems to organizations (Holsapple et al, 2019):

- They have integration and standardization capacities.

- $\quad$ Their server architecture is very flexible.

- The ability of ERP systems to push for effective business reengineering.

- The ability for management of core and support processes.

Many organizations have adopted ERP systems due to how effective the system is. The system comes highly recommended by vendors and system consultants due to the business practices in their system packages. 


\section{METHODOLOGY}

In this part, the research will introduce the design and methodology that will be used in this study. This part will cover the sampling, the data collection and the methodology that we will use in the study, in addition to the identification of the dependent variables and independent variable in each hypothesis.

\section{Research Design}

In this research, the quantitative research method will be used to collect data and analyze it. Our study is designed to quantify the relationship between the dependent and the independent variables. The samples will help us testing the hypotheses. The study was conducted in local and multinational audit firms in Lebanon.

\section{Data Collection}

The data collection technique aims to evaluate the collection process implemented in the research. Two types of data were implemented and they are the primary and the secondary data. The primary data is throughout distributing a survey for collecting data, as for the secondary data it had been through addressing previous studies and researches done before.

The quantitative method had been implemented throughout using a survey based on the research variables in order to test the research hypotheses later on. The questionnaire had been distributed to leading companies and banks in Lebanon to gather different data based on experience and different point of views.

The Likert scale had been implemented to measure the responses of the questionnaire using a nominal scale, and a list of statements had been constructed based on authentic information and measuring the variable is based on a range of agreement and disagreement among auditors to study the relationship between ERP and Performance Audit. The survey answers are confidential and will be used for academic purposes only.

\section{Sampling}

The sampling sub-section, will explain the sampling means and the nature of the methods applied in this study, to decide upon the criteria of the participants needed to fill this questionnaire.

For the purpose of testing the hypothesis of this research the questionnaire targeted audit firms, banks and managers in multinational companies in Lebanon. This selection of participating firms allowed the researcher to have a clearer understanding regarding the potential relationship between the different research variables that exist Lebanese audit firms. This is a convenient type of sampling that has been 
based on a personal understanding of the Lebanese auditing firms, in relation to the purpose and scope of this research.

The participants were auditors working in Lebanese auditing firms, regardless of their position within the auditing firms. The auditors sampled works in several types of services; such as assurance and audit, advisory, transaction services, tax and internal audit. The managers of the multinational companies are CFO or chief accountants. The diversification of the sample allows it to be fairly representative of the variety of the people included in our study and to represent different perspectives.

Each participant is an auditor in an audit firm, bank or a multinational company, and has filled only one questionnaire. The participants were informed that the survey is completely confidential and that it was sent for academic research purpose.

The online survey allowed us to collect the required information in the shortest time possible. In addition, as it is mentioned before, the concept of sending online survey, helps the participants complete the survey with freedom. This method will ensure objectivity and anonymity in the answers which insures effective results. This method will increase ease in filling questions that will urge participants to answer honestly. The participant will take his/her time to finish the questionnaire. Online survey elaborates quick results as soon as the participants answers the survey.

Even though the online survey has many advantages, the participants do not give importance to online surveys which can create an issue in the final result of our study. Sometimes the participants may answer the questionnaire before completely reading the question, and consequently hey can affect the validity and reliability of our collected data.

Finally, as it is revealed before, the questionnaire had been distributed for 150 auditors or financial mangers working in different companies in order to get their perceptions on the relationship between continuance auditing and ERP performance. The questionnaires have received a total of 120 responses completely filled and received at the end of the data collection process.

\section{Variables and Hypotheses}

The dependent variable is known as the endogenous variable and it is affected by the independent variables. The dependent variable of the research is Audit Performance.

As for the independent variables are the variables which affect the dependent variable and they are continuous audit and audit processes.

As for the research hypotheses, it will be constructed based on the research variables mentioned above:

$>$ HO: There is an indirect relationship between the continuous audit and performance audit.

> H1: There is a direct relationship between continuous audit and performance audit.

$>$ H0: There is an indirect relationship between audit processes and performance audit. 
Serhan A.

THE IMPACT OF ERP AUDIT ON MEASURING ORGANIZATIONAL PERFORMANCE: THE CASE OF LEBANON

H1: There is a direct relationship between audit processes and performance audit.

\section{FINDINGS}

The regression analysis had been conducted to test the relationship between dependent and independent variables. However, the results will be viewed in the below tables to test the research hypotheses.

TABLE 1. RELATIONSHIP BETWEEN AUDIT PRACTICES AND PERFORMANCE AUDIT

Model Summary

\begin{tabular}{|l|r|r|r|c|}
\hline Model & $\mathrm{R}$ & $\mathrm{R}$ Square & \multicolumn{1}{|c|}{$\begin{array}{l}\text { Adjusted } \mathrm{R} \\
\text { Square }\end{array}$} & $\begin{array}{l}\text { Std. Error of the } \\
\text { Estimate }\end{array}$ \\
\hline 1 & $.491^{\mathrm{a}}$ & .281 & .233 & .75842 \\
\hline
\end{tabular}

a. Predictors: (Constant), ERP

\section{Coefficients}

\begin{tabular}{|c|c|c|c|c|c|}
\hline \multirow[t]{2}{*}{ Model } & \multicolumn{2}{|c|}{ Unstandardized Coefficients } & \multirow{2}{*}{$\begin{array}{c}\text { Standardized Coefficients } \\
\text { Beta }\end{array}$} & \multirow[t]{2}{*}{$\mathrm{t}$} & \multirow[t]{2}{*}{ Sig. } \\
\hline & B & Std. Error & & & \\
\hline \multirow{2}{*}{$\begin{array}{ll}1 & \text { (Constant) } \\
& \text { Audit Practices }\end{array}$} & .468 & .144 & & 1.916 & .000 \\
\hline & 9.381 & 1.753 & .491 & 5.574 & .030 \\
\hline
\end{tabular}

a. Dependent Variable: Performance

Source: Generated in SPSS

The above regression analysis had been conducted to test the relationship between the research variables. The significance level showed a level of 0.003 which is lower than 0.05 which means that the null hypotheses which state that "There is an insignificant relationship between audit practices and performance audit" had been rejected, and accepting the alternative hypotheses which states that "There is a significant relationship among process audit practices and performance audit" is accepted.

As for the R-Square it showed a level of $28.1 \%$, meaning that there is a strong relationship among the mentioned variable.

TABLE 2. RELATIONSHIP BETWEEN CONTINUOUS AUDIT AND PERFORMANCE

\begin{tabular}{|l|c|r|r|c|}
\hline Model & $R$ & $\begin{array}{c}\text { R } \\
\text { Square }\end{array}$ & $\begin{array}{c}\text { Adjusted R } \\
\text { Square }\end{array}$ & $\begin{array}{c}\text { Std. Error of the } \\
\text { Estimate }\end{array}$ \\
\hline 1 & \multicolumn{1}{|c|}{$.521^{\mathrm{a}}$} & .271 & .264 & .74312 \\
\hline
\end{tabular}

a. Predictors: (Constant), Continuous Audit 
Serhan, A.

THE IMPACT OF ERP AUDIT ON MEASURING ORGANIZATIONAL PERFORMANCE: THE CASE OF LEBANON

\section{Coefficients}

\begin{tabular}{|c|c|c|c|c|c|}
\hline \multirow[t]{2}{*}{ Model } & \multicolumn{2}{|c|}{ Unstandardized Coefficients } & \multirow{2}{*}{$\begin{array}{c}\text { Standardized } \\
\text { Coefficients } \\
\text { Beta }\end{array}$} & \multirow[t]{2}{*}{$\mathrm{t}$} & \multirow[t]{2}{*}{ Sig. } \\
\hline & $B$ & Std. Error & & & \\
\hline (Constant) & .631 & .201 & & 3.134 & .000 \\
\hline $\begin{array}{l}\text { Continuous } \\
\text { Audit }\end{array}$ & 8.543 & 1.415 & .521 & 6.036 & .004 \\
\hline
\end{tabular}

a. Dependent Variable: Performance

Source: Generated in SPSS

The above regression analysis had been conducted to test the relationship between the research variables. The significance level showed a level of 0.004 which is lower than 0.05 which means that the null hypotheses which state that "There is an insignificant relationship between continuous audit and performance" had been rejected, and accepting the alternative hypotheses which states that "There is a significant relationship among continuous audit and performance" is accepted.

As for the R-Square it showed a level of $27.1 \%$, meaning that there is a strong relationship among the mentioned variable.

However, the regression analysis can be explained in the below equation:

$Y=a+B X 1+B X 2$

$Y=$ dependent variable (Performance audit)

$X=$ independent variables (Continuous audit and audit procedures)

$\mathrm{B}=$ Coefficient

Then, $Y=a+0.03$ audit procedures +0.004 continuous auditing

This means that for every one-unit increase in audit procedures, the performance audit will be affected by 0.03 , and for every one-unit increase in continuous auditing, the performance audit will be affected by 0.004 .

ERP systems have a number of influences on organizational performance ranging from operational to strategic. In this regard, it is important to understand the difference between operational efficiency and strategic success. Operational efficiency is mostly reflected in cost reduction and productivity enhancement while strategic success is seen in revenue growth and market share gains.

With EPR systems there is attainment of operational efficiency and rise in liquidity. The most widely used ERP systems are financial ERP systems that are used for measuring firm performance as well as business process performance. The biggest advantage of an EPR system is it capability to provide realtime information meaning that it is capable of observing and accessing all organizational activities as they 
happen. Still success cannot be quantified to access of all organizational data as key parts of information need to be focused on in order to separate failure and success. With all the data being in one system in an ERP, organizations management can be able to improve business as the system is able to integrate business processes, navigate numerous functions as well as geographical locations.

Implementation of Enterprise systems have had negative impact in that innovative opportunities have had challenges in handling internal as well as external risks. Internal auditors from an internal auditing perspective noticed a decrease in financial and operational risk as well as an increase in technical risks as an auditor possessing knowledge and skills in computerized information is important as ERP systems are very technical. When it comes to measuring risk factors for implementation and usage of ERP system, they are measured reviewing them against organizations process control objectives.

There are two categories of measures when it comes to evaluating the performance of an ERP system. They include financial and technical view. There are certain limitations involved with financial evaluations. First, cost cannot be easily revised as they were already decided on hence information is limited. Secondly, it is hard the valuation of intangible goods connected with an ERP information system. If an organization intends on using the balanced scorecard to control ERP software running, the four perspectives of balanced scorecard need to be adjusted to object of ERP system. The four perspectives include; the customer perspective, financial perspective, internal process perspective and innovation and learning perspective.

\section{CONCLUSION}

The study provides practical insights on the implementation of ERP systems into organizations. An ERP implementation basically entails a large information system implementation project that has huge impact on major areas of the organization that implements it.

The objective of the research was to come up with a continuous auditing framework of performance management for ERP system. The research shows that the combined use of process and system determines performance. With the increase in fraud, bankruptcy and financial report restatements, ensuring the integrity of accounting information and audit profession is important. This research has analyzed literature on continuous auditing as well as ERP systems and how they have been influential to organizations. 


\section{REFERENCES}

Abdolmohammadi, M. and Boss S. (2010) Factors associated with IT audits by the internal audit function, International Journal of Accounting Information Systems, 11, 3, 140-151.

Chen, H., Huang,S. Y., Chiu, A. and Pai, F. (2012) The ERP system impact on the role of accountants, Industrial Management and Data Systems, 112, 1, 83-101.

Ebaid, I.E. (2011) Internal audit function: an exploratory study from Egyptian listed firms, International Journal of Law and Management, 53, 2, 108-128.

Elragal, A. A., \& Ayman, M. Al-Serafi. (2011). The Effect of ERP System Implementation on Business Performance: An Exploratory Case-Study. Communications of the IBIMA, 2011.

Gosain, S. (2004) Enterprise Information Systems as Objects and Carriers of Institutional Forces: The New Iron Cage? , Journal of the Association for Information Systems, 5, 4,151- 182.

Grabski, S. V., Leech, S. A. and Schmidt, P. J. (2011) A Review of ERP Research: A Future Agenda for Accounting Information Systems, Journal of Information Systems, 25, 1, 37-78.

Holsapple, C., Sena, M., \& Wagner, W. (2019). The perceived success of ERP systems for decision support. Information Technology and Management, 20(1), 1-7.

Kanellou, A. and Spathis, C. (2011) Auditing in enterprise system environment: a synthesis, Journal of Enterprise Information Management, 24, 6, 494-519.

Kholeif, A., Abdel-Kader, M. and Sherer, M. (2007) ERP Customization Failure: Institutionalized Accounting Practices, Power Relations and Market Forces, Journal of Accounting and Organizational Change, 3, 3, 250-299.

Lee, Z., \& Lee, J. (2000). An ERP implementation case study from a knowledge transfer perspective. Journal of information technology, 15(4), 281-288.

Rezaee, Z., Elam, R., \& Sharbatoghlie, A. (2001). Continuous auditing: the audit of the future. Managerial Auditing Journal.

Searcy, DeWayne L.; Woodroof, Jon B. Continuous auditing: leveraging technology. The CPA Journal, v. 73 , n. 5, p. 46-8, May 2003. 